\title{
COMPARISON OF THE ANXIETY LEVELS BETWEEN THE FAMILY MEMBERS OF THE PATIENTS PRESENTING TO THE PAEDIATRIC TRAUMA UNIT AND PAEDIATRIC EMERGENCY UNITS
}

\author{
Abdullah Osman Koçak ${ }^{1}{ }^{\infty}$, İlker Akbaş $^{2}{ }^{\infty}$, Sultan Tuna Akgöl Gür ${ }^{1} \mathbb{D}_{\text {, }}$ \\ Meryem Betos Koçak ${ }^{3}$, Halil Keskin ${ }^{4}$, Zeynep Çakır ${ }^{1}$ (1) \\ 'Department of Emergency Medicine, Faculty of Medicine, University of Ataturk, Erzurum, Turkey \\ ${ }^{2}$ Department of Emergency Medicine, Bingöl State Hospital, Bingol, Turkey \\ ${ }^{3}$ Department of Family Medicine, University of Ataturk, Erzurum, Turkey \\ ${ }^{4}$ Department of Pediatrics, Faculty of Medicine, University of Ataturk, Erzurum, Turkey
}

\begin{abstract}
INTRODUCTION: It is not the right behaviour to accept every anxiety pathologically. On the contrary, the sense of anxiety is an indicator of the response of individuals to internal or external changes. More importantly, anxiety is a beneficial affective state for individuals who contribute to the development of self and bodily adaptability to the new environment in which they live.
\end{abstract}

MATERIAL AND METHODS: This is a prospective study. The study was conducted on the parents of the patients who applied to the paediatric emergency department and paediatric trauma units of the emergency department at Atatürk University Faculty of Medicine. Beck Anxiety Scale was administered to one of the relatives who brought the patient to the hospital. Beck anxiety test was filled in by using face-to-face interview method. Pre-defined study forms for patients included in the study were completed.

RESULTS: The study was completed with 68 family members in both groups. The values of the patients who were admitted to the paediatric emergency and adult emergency departments on the Beck Anxiety Scale were equal.

CONCLUSIONS: family members of paediatric patients admitted to hospital were compared; The family members of the paediatric trauma unit and the family members of the paediatric emergency department have the same level of anxiety.

KEY WORDS: anxiety; paediatric patients; emergency; paediatric trauma unit; family members

Disaster Emerg Med J 2019; 4(4): 147-150

\section{INTRODUCTION}

The word anxiety is derived from the word angh, which means sore throat, distress. The word Angh comes from the Indo-Germanic language family. The state of anxiety was first mentioned in the Gil- gamesh epic, written in 3000s before Christ [1, 2]. In short, anxiety is an individual's response to environmental or physical changes for attack and defence purposes. The basis of their actual behaviour is to preserve the self, integrity and values that exist 
in that individual due to the inheritance inherited from the evolutionary process $[3,4]$. It is not correct behaviour to accept each anxiety pathologically. On the contrary, the sense of anxiety is an indicator of the response of individuals to internal or external changes. More importantly, anxiety is a beneficial affective state for individuals who contribute to the development of self and bodily adaptability to the new environment in which they live [5]. However, exaggerated responses to internal or external stimuli, it is inevitable that any condition that damages the self-integrity of people affects socially negatively and even disrupts body physiology is inevitable [3].

\section{MATERIAL AND METHODS}

\section{Study design and setting}

This is a prospective study. The study was conducted with face to face interviews with the family members of the patients admitted to the paediatric emergency department and paediatric trauma units of the emergency department of Atatürk University School of Medicine. The study was conducted on 01.10.2016-31.01.2017.

\section{Patients}

In the paediatric trauma emergency department in our hospital, services are provided to paediatric trauma patients. In the paediatric emergency unit, patients without trauma are served. patients with fever, nausea and vomiting. Our study was carried out after the consent of the accompanying persons (only the mother or father was asked to fill the scale) of the patients who applied to the paediatric emergency department of our hospital's paediatric health and diseases. Companions who did not give written consent and who were life-threatening in their patients were not included in the study.

\section{Measurements}

The pre-determined study forms were completed for the patients included in the study. The diagnoses of the patients, patient genders, family member ages, family member genders and scores from the Beck Anxiety Scale were recorded. Beck anxiety test was filled in by using a face-to-face interview method.

\section{Beck Anxiety Scale}

It is a self-assessment test. It is used to investigate the frequency of anxiety symptoms experienced by individuals. Likert type is measured. In our country, reliability and validity studies have been made and accepted. The test consists of 21 items. For each item, the participant is asked to score between $0-3$. According to the answers given, the severity of the anxiety experienced by the people is determined.

\section{Statistics}

The analyses were performed with IBM SPSS 20 statistical analysis program. Data were presented as mean, standard deviation, median, minimum, maximum, percentage and number. Shapiro-Wilk and Kolmogorov-Smirnov tests were used to evaluate the normal distribution of continuous variables. In the comparison between two independent groups, the Independent Samples t-test was used when the normal distribution condition was satisfied, and the Mann-Whitney $U$ test was used when not provided. The comparison between the categorical variables was made using the Chi-square test and Fisher's Exact test. Statistical significance level was taken as $p<0.05$.

\section{RESULTS}

The study was completed with 68 family members of patients who applied to the emergency department and 68 family members of patients with trauma to the emergency department. 37 patients admitted to the paediatric trauma units of emergency department were male and 34 of the family members of the patients admitted to the paediatric trauma units emergency department were male. The most common reason for admission to the paediatric emergency department was fever with 51 patients. This was followed by vomiting in 10 patients and diarrhoea in 7 patients. The majority of the patients admitted to the paediatric trauma units of emergency department were admitted after the fall $(n=60) .8$ patients were admitted after a traffic accident. The mean age of the parents of the patients admitted to the paediatric emergency department was $33.09 \pm 7.46$. The mean age of the parents of the patients admitted to the paediatric trauma emergency was $32.88 \pm 9.06$ ( $p>0.05)$. According to the results of the beck anxiety test applied to the parents of the paediatric patients included in the study; The mean value of the parents of the patients who applied to the paediatric emergency department was $10.85 \pm 9.17$ and the value of the parents of the patients who applied to the paediatric 
Table 1. Beck depression test scores and the mean age of parents

\begin{tabular}{|l|c|c|}
\hline & $\begin{array}{c}\text { Beck Depression } \\
\text { Test scores }\end{array}$ & The Mean Age \\
\hline $\begin{array}{l}\text { Paediatric Emergency } \\
\text { Department }\end{array}$ & $10.85 \pm 9.17$ & $33.09 \pm 7.46$ \\
\hline $\begin{array}{l}\text { Paediatric Trauma } \\
\text { Emergency Department }\end{array}$ & $10.90 \pm 6.40$ & $32.88 \pm 9.06$ \\
\hline
\end{tabular}

trauma emergency was $10.90 \pm 6.40(p>0.05)$. According to Beck Depression Test scores, this was not clinically significant.

\section{DISCUSSION}

Anxiety occurs in life-threatening events as a normal reaction to life events such as separation from a loved one or environment, physical illnesses. Along with anxiety, autonomic and somatic symptoms are seen at the same time. This prevents further damage as a protective mechanism. In some cases, the stimuli coming from the inner world of the individual without any external stimuli can cause an anxiety sensation to develop automatically. If the defence mechanisms in individuals are meaningfully healthy, they can cope with controlling anxiety, but if individuals are not fully mentally healthy, the anxiety may become chronic. If a person cannot control his or her anxiety, a mental disorder called anxiety disorder occurs. Anxiety disorders have a higher prevalence of life in women (30\%) than men (19\%). This ratio decreases in those with high socioeconomic status $[6,7]$. Anxiety is distinguished from other forms of effect by unpleasant features. Anxious person may develop psychological symptoms such as anxiety, excitement, a sudden bad feeling or suspicion. The difference between anxiety and fear is that the source of anxiety is often uncertain. Mild anxiety accelerates the process of adapting to new conditions in individuals and supports their mental development. mild anxiety, therefore, is a useful feeling for people. There is an optimal range in which anxiety positively affects a person's performance. in people above these levels it can cause adversities. Anxiety above a certain level no longer acts as adaptive but acts as a barrier. The extent of the adaptive and nonadaptive effects of anxiety should be well established. Anxiety states that include physical symptoms such as muscle tension, dry mouth, palpitations and tremors that cause impaired inter-human ties, which decrease the occu- pational functions of chronic individuals should be considered pathologically [8]. Generally, the economic situation can cause problems in the workplace, health problems, problems of children, housework and any event in the social environment. In addition, it can be seen in somatic symptoms as a cause of stress [9-11]. Generalized anxiety disorder is a disorder that is associated with feelings of significant tension, anxiety, worries about everyday events and, often chronic and sometimes intermittent, and this condition decreases quality of life $[12,13]$.

It has been described according to DSM- 5 of the anxiety disorder related to another health condition $[14,15]$. Accordingly, anxiety may also develop due to health problems. The aim of this study was to investigate whether the parents of the paediatric patients who admitted to the hospital urgently had more anxiety in cases such as falls, admission to the emergency department after traffic accidents and nausea. In our study, it was found that the parents of paediatric patients who applied to both the paediatric trauma emergency department and the paediatric emergency department had the same level of anxiety.

\section{CONCLUSIONS}

Irrespective of the complaints of the children's emergency admission to the hospital, it causes the same level of anxiety in family members. Paediatric patients are a particularly important group of patients for families. Families are protective of their children and are concerned about their hospital application. In our study, emergency department applications of children were studied. According to the results of the study, it was found that the families of the patients who applied to the paediatric emergency department and who applied to the paediatric trauma emergency department had similar levels of concern. the reason for this is that all emergency applications should be given equal priority regardless of the reason for the application of the families. All families are equally concerned about their children.

\section{REFERENCES}

1. Tukel R, Mental T. Anxiety Disorders. Turkey Psychiatric Association Publications, Ankara 2006.

2. Maranets I, Kain ZN. Preoperative anxiety and intraoperative anesthetic requirements. Anesth Analg. 1999; 89(6): 1346-1351, doi: 10.1097/00000539-199912000-00003, indexed in Pubmed: 10589606. 
3. Balcıoğlu i.. Psychoendocrinology of anxiety disorders. Anatolian Journal of Psychiatry. 2002; 3(1): 45-51.

4. Machelart G, Tignol A. Anxiété et dépression. Psychol Med. 1989; 21: 1-22.

5. Karamustafalıoğlu 0, Yumrukçal H. Depression and anxiety. Review. The Medical Bulletin of Şişli Etfal Hospital. 2011; 45(2).

6. Nutt $D$, Argyropoulos $S$, Forshall S. Generalized Anxiety Disorder: Diagnosis, treatment and its relationship to other anxiety disorders. Martin Dunitz, London 1998: 1-4.

7. Mercan S, Altunay K. Psychodermatology: A collaborative subject of psychiatry and dermatology. Turk J Psych. 2006; 17: 1-9.

8. Karamustafalıoglu 0, Akpınar A. Anxiety disorders. Psychiatry for Family Physicians. 1st Edition. MT International Publishing, Istanbul 2010: 71-88.

9. Patient evaluation and treatment in anxiety and panic attacks Dr. View Alaattin Duran's Full Profile Cerrahpaşa Faculty of Medicine Continuing Medical Education Activities Symposium on Depression,
Somatization and Psychiatric Emergencies 2-3 December. Istanbul 1999: 145-156.

10. Dilbaz N. Recent Develoments in Anxiety Disorders. Positive Printing, Ankara 2005: 59-78.

11. Öztürk 0 , Uluşahin A. Mental Health and Diseases new press 11th Edition 1. Vol, Ankara 2008: 452.

12. Çuhadaroğlu F, Kaplan G, Özgen G. Dünya Sağlık Örgütü ICD-10 Ruhsal ve Davranışsal Bozukluklar Sınıflandırması, Klinik Tanımlamalar ve Tanı Kılavuzlar. Ankara Medikomat. 1993.

13. Cuhadaroglu F, Kaplan I, Ozgen G. World Health Organization. ICD-10, Mental and Behavioral Disorders Classification, Clinical Definitions and Diagnostic Guidelines 1992. Ankara: Ozhan Printing. 1993.

14. Shorter E. A history of psychiatry: From the Era of the Asylum to the Age of Prozac. John Wiley\&Sons Inc, New York 1997.

15. American Psychiatric Association. Diagnostic and Statistical Manual of Mental Disorders, Fifth Edition (DSM-5), Diagnostic Criteria Reference Handbook. Association of Physicians, Ankara 2013. 